\title{
Outcome of management of severe acute malnutrition at nutrition rehabilitation centre and follow up
}

\author{
Suguna S. \\ Associate Professor, Dept. of Paediatric, Chamarajanagar Institute of Medical Sciences, Chamarajanagar, Karnataka, India
}

*Corresponding Author:

Email: sugunasmysore@gmail.com

\begin{abstract}
Objective: To know the sustained weight gain of severe acute malnutrition children during in patient care and during follow-up visits at nutrition rehabilitation centre and to assess the overall performance of Nutrition rehabilitation centre.

Material and Methods

Setting: Nutrition rehabilitation centre, District hospital, chamarajanagar attached to chamarajanagar institute of medical sciences, chamarajanagar

Design: This is a retrospective study involving the review of existing programme records.

Population: Those children who are admitted to NRC, district hospital chamarajanagar, Karnataka, India, between January 2017 to January 2018 with severe acute malnutrition.

The programme included 2 weeks of in-patient care, and four follow-up visits to the NRC subsequently as follows ; $1^{\text {st }}$ visit at 7 days, $2^{\text {nd }}$ at 14 days, $3^{\text {rd }}$ at 1 month and $4^{\text {th }}$ at 2 months after discharge.

Result: Among total 61 admissions between January 2017 and January 2018, 57 children completed 14 days treatment (93.44\%). 4 children were discharged against medical advice

and could not complete 14 days treatment and were taken as defaulters $(6.55 \%)$.

$57.8 \%$ children reached $<-2$ SD and $21.06 \%$ children reached $<-1$ SD at the time of discharge.

Those children who could achieve <-1SD during entire programme including follow up were 32(56\%) among 57 admissions.

Conclusion: Satisfactory weight gain could not be achieved as per national programme requirement either during inpatient care or during follow up visits. There was sustained weight gain with cure of associated illnesses during NRC care satisfying discharge criteria. The follow up visits to NRC after discharge was satisfactory (>93\%) till the target weight gain of $<-1 \mathrm{SD}$ is achieved.
\end{abstract}

Keywords: Severe acute malnutrition (SAM), NRC (Nutrition rehabilitation centre), Anthropometric measurements, RBSK (Rashtriya Bal Swasthya Karyakram).

\section{Introduction}

In 2013, an estimated 2.9 million children under five were admitted globally for treatment of severe acute malnutrition (SAM). This figure represents significant progress when compared with just over 1 million reported during 2009 (UNICEF Nutrition Section 2013) yet is clearly insufficient when compared to the global burden of 17 million children affected by SAM (UNICEF, WHO, World Bank 2014). Children with SAM are nine times more likely to die than wellnourished children. ${ }^{1}$

As per National Family Health Survey (NFHS)-4 (2015-16), In India, 38 percent of children under age five years are stunted (too short for their age). This is a sign of chronic undernutrition. Twenty-one percent of children under age five years are wasted (too thin for their height), which is a sign of acute undernutrition, while 36 percent of children under age five years are underweight. The prevalence of stunting and underweight has decreased since 2005-06, especially for stunting, which declined from 48 percent in 2005-06 to 38 percent in 2015-16. Over this same time period, the prevalence of wasting has remained about the same. ${ }^{2}$

Decision for home or outpatient and inpatient care depends on the facility available for management of these children and the associated complications. There is growing evidence that SAM without complications does not require inpatient treatment and can be effectively managed at the community level. Children who are discharged early from inpatient care also may be managed at the community level. SAM children with medical complications should be admitted and managed in a health facility. ${ }^{3}$ (Fig. 1).

Nutritional rehabilitation Centre is the Facility Based unit made available in many Indian states with the advent of the National Rural Health Mission ${ }^{4}$ for the treatment of SAM children. ${ }^{5}$

\section{Material and Methods}

Design: This is a retrospective study involving the review of existing programme records.

Population: Those children who are admitted to NRC, district hospital chamarajanagar, Karnataka, India, between January 2017 to January 2018 with Severe acute malnutrition.The NRCs has been operational for more than 5 years, Karnataka, India.

The study aimed to know the sustained weight gain of SAM children during NRC in patient care and during 
follow-up visits and to assess the overall performance of NRC functioning in chamarajanagar.

The operational guidelines of NRC setup were according to National Rural Health Mission/RCH-phase II. $^{3}$

The NRCs consist of 10 bedded ward with a kitchen, toilet facility and demonstration room. Children aged 6months to 5 years are referred to the NRC by RBSK, Anganwadi workers/ASHA workers, pediatricians, or approached by parents themselves in some cases.

The admission and discharge criteria are laid out in the national guidelines. ${ }^{3} \mathrm{NRCs}$ function along the lines of the WHO and revised Indian Association of Paediatrics (IAP) protocols. ${ }^{6}$

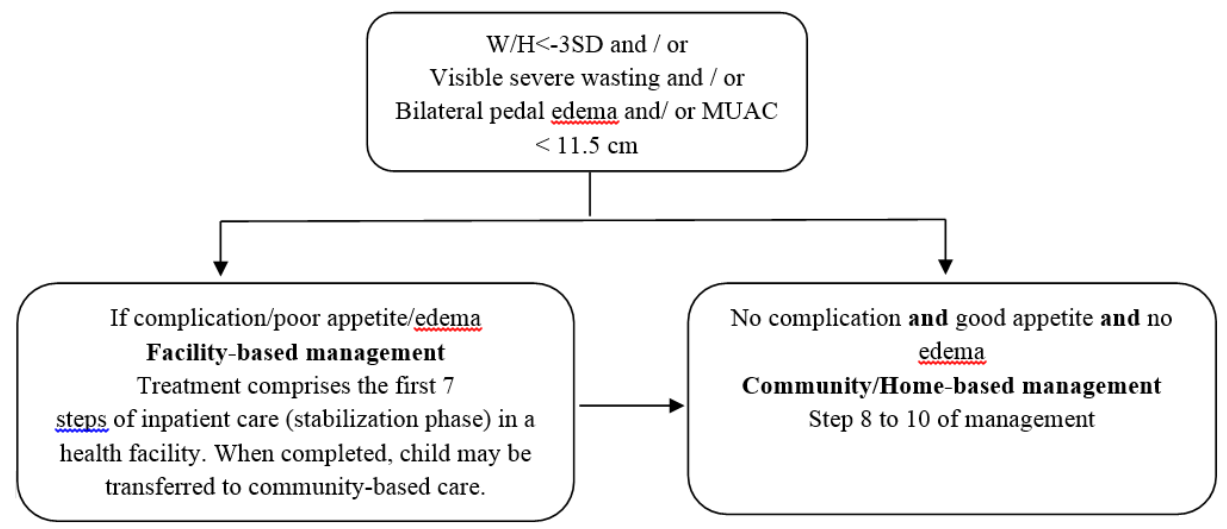

Fig. 1: Criteria for Facility-based care

Table 1: 10 Steps of routine care

\begin{tabular}{|ll|}
\hline 1. & Treat/prevent hypoglycaemia \\
\hline 2. & Treat/prevent hypothermia \\
\hline 3. & Treat/prevent dehydration \\
\hline 4. & Correct imbalance of electrolytes \\
\hline 5. & Treat infections \\
\hline 6. & Correct deficiencies of micronutrient \\
\hline 7. & Start cautious feeding \\
\hline 8. & Rebuild wasted tissues (catch-up growth) \\
\hline 9. & Provide loving care and play \\
\hline 10. & Prepare for follow -up \\
\hline
\end{tabular}

\section{Admission criteria ${ }^{3}$}

Severe acute malnutrition (SAM) among children aged 6-59 months with

1. Weight-for-height/length Z-score $($ WHZ) $<-3$ (Zscore in standard deviations [SDs] reflects the deviation from the median of World Health Organization [WHO] child growth standards)

2. Mid-upper arm circumference (MUAC) < $115 \mathrm{~mm}$ or

3. Presence of nutritional oedema.

\section{Indicators ${ }^{3}$ :}

1. Relapse: a patient who has been discharged as cured from the programme within the last 2 months but is again eligible for admission to NRC.

2. Defaulter: number of beneficiaries that defaulted during the reporting period divided by the total exits. Defaulter will be a child with SAM admitted to the ward but absent (from the ward) for three consecutive days without been discharged.

3. Non-respondent: this exit category includes those beneficiaries who fail to respond to the treatment.
4. Referral By- RBSK/Asha worker/pediatric $\mathrm{OPD} / \mathrm{self}$.

5. Weight gain achieved target weight $(15 \%$ weight gain)

6. Referral to higher center

7. Case fatality rate

Performance of NRC may be assessed based on the criteria described below (Table 2).

Table 2: Quantitative Indicators

\begin{tabular}{|l|l|l|}
\hline & Acceptable & Alarming \\
\hline Recovery rate & $>75 \%$ & $50 \%$ \\
\hline Death rate & $<10 \%$ & $>15 \%$ \\
\hline Defaulter rate & $<15 \%$ & $>25 \%$ \\
\hline Weight gain & $>8 \mathrm{~g} / \mathrm{kg} /$ day & $<8 \mathrm{~g} / \mathrm{kg} /$ day \\
\hline Length of stay & $<4 \mathrm{wks}$ & $>6 \mathrm{wks}$ \\
\hline
\end{tabular}

Guidance for calculation of indicators ${ }^{3}$ :

Weight Gain $(\mathrm{g} / \mathrm{kg} / \mathrm{d})$

Weight gain $=\{$ discharge weight in gms - minimum weight in gms $\} /\{$ minimum weight in $\mathrm{kg} \mathrm{x}$ number of 
days between date of minimum weight and discharge day\}

All SAM children should be followed up by health providers in the program till s/he reaches weight-forheight of - 1SD.

Therapeutic diet is made of locally available food for a minimum of 14 days and accompanied by the mother / the primary care giver.

Initial feeding begins with F-75 with $75 \mathrm{kcal}$ and $0.9 \mathrm{~g}$ protein per $100 \mathrm{ml}$. when child is stabilized (usually after 2-7 days) Catch up diet (F-100) with 100 $\mathrm{kcal}$ and $2.9 \mathrm{~g}$ proteins per $100 \mathrm{ml}$ is given.
Vitamin A is given to all severely malnourished children on Day 1. Timing and oral dosage of Vitamin A includes - < 6 months, $50000 \mathrm{IU}$; 6-12 months or if weight <8Kg, $100000 \mathrm{IU}$; > 12 months, $200000 \mathrm{IU}^{3}$.

Weight, height and MUAC, are monitored using standard techniques guidelines. Mother / primary care giver is counseled and educated on the composition and preparation of therapeutic diets.

Children are discharged according to the criteria given below (Table 3)

Table 3: Prepare for discharge and follow up after recovery ${ }^{3}$

\begin{tabular}{|l|l|}
\hline Criteria for discharge from inpatient care \\
\hline Child & $\begin{array}{l}\text { 1. Edema has resolved } \\
\text { 2. Achieved weight gain of } \geq 15 \% \text { and has } \\
\text { satisfactory weight gain for } 3 \text { consecutive days (>5 } \\
\text { gm/kg/day) }\end{array}$ \\
$\begin{array}{l}\text { 3. Child eating an adequate amount of nutritious food } \\
\text { that the mother can prepare at home }\end{array}$ \\
$\begin{array}{l}\text { 4. All infections and other medical complications } \\
\text { have been treated }\end{array}$ \\
$\begin{array}{l}\text { 5. Child is provided with micronutrients } \\
\text { 6. Immunization is updated }\end{array}$ \\
\hline Mother/caregiver \\
$\begin{array}{l}\text { Knows how to prepare appropriate foods and to feed } \\
\text { the child } \\
\text { Knows how to make appropriate toys and play with the } \\
\text { child } \\
\text { Knows how to give home treatment for diarrhea, fever } \\
\text { and acute respiratory infections, and how to recognize } \\
\text { the signs that/he must seek medical assistance } \\
\text { Follow-up plan is completed }\end{array}$ \\
\hline
\end{tabular}

Follow-up visits after discharge to NRC include; $1^{\text {st }}$ visit at 7 days, $2^{\text {nd }}$ at 14 days, $3^{\text {rd }}$ at 1 month and $4^{\text {th }}$ at 2 months after discharge. All SAM children followed up till he/she reaches weight-for-height of -1 SD.

\section{Data variables, sources and definitions}

The data are collected from NRC admission registers maintained at Medical record section, district hospital, chamarajanagar. The follow up records are collected from follow up registers maintained at NRC.

\section{Results}

Among total 61 admissions between January 2017 and January 2018, 57 children completed 14 days treatment(93.44\%). 4 children were discharged against medical advice and could not complete 14 days treatment and were taken as defaulters $(6.55 \%)$. There were no referral to higher centre and no deaths during the above said period.

\section{Data analysis}

Data is analysed done by SPSS version 16 . Descriptive statistics and chi-square test for independence used for statistics.
The mean weight at the time of admission was $7.46 \mathrm{~kg}$, and standard deviation of 1.53 ; minimum weight of 4.5 $\mathrm{kg}$ and maximum weight of $11.5 \mathrm{~kg}$.

At the time of discharge there was increase in the mean weight of $7.92 \mathrm{~kg}$ and standard deviation of 1.57 ; minimum weight of $5.05 \mathrm{~kg}$ and maximum $12.65 \mathrm{kgs}$.

Mean age of admission was 23.3 months with minimum of 10 months and maximum of 54 months.

Females were 30 and males 27 among 57 cases. There was no statistical significant association with sex ratio either in number of admissions or in severity of malnutrition ( $\mathrm{p}=0.451)$ (Table 4).

The mean mid arm circumference was 11.74 with standard deviation of 0.613 .

Majority of children were identified at pediatric OPD (41\%), 5\% from RBSK, $8 \%$ from Asha /AWW and 12\% were approached by parents themselves.

At the time of admission, majority of children were <-3 SD $(61.4 \%)$ weight for height (WFH), <-2SD were $29.8 \%, 7 \%$ were <-4SD and 1 child was <-1SD $(1.8 \%)$ with severe loss of appetite and associated anaemia (Table 5).

WFH at the time of discharge were, children with <$3 \mathrm{SD}$ were $19.3 \%$, <-4SD were $1.8 \% ; 57.9 \%$ children 
reached $<-2 \mathrm{SD}$ and $21.1 \%$ children reached $<-1 \mathrm{SD}$ (Table 6).

$5(8.7 \%)$ among 57 children could gain weight of $>8$ gram $/ \mathrm{kg} /$ day in 14 days NRC care; as per quantitative indicator of satisfactory weight gain (Table 2).

25 among 57 children (43.9\%) could sustain weight gain of $>5 \mathrm{grams} / \mathrm{kg} /$ day as per one of the discharge criteria (Table 3). 13 were females and 12 were males (Fig. 2). Chi-square test for independence showed no association between sex of child and gaining weight $(\mathrm{p}=0.933)($ Table 7$)$.

Those children who could achieve <-1SD during entire programme including follow up were 32(56\%) among 57 admissions. 12 children (21\%) reached <-1SD at the time of discharge, $7(12 \%)$ at the time of first follow up visit( $7^{\text {th }}$ day), $3(5 \%)$ at second follow up visit(14 ${ }^{\text {th }}$ day), $6(11 \%)$ at third follow up visit(1month), $2(3 \%)$ children at $2^{\text {nd }}$ month and $2(4 \%)$ children one month later (Fig. 3).

Associated factors at the time of admission were, Anemia in 41children (71.9\%), anorexia in 13 children, infection in 6 children, 3 with RTI and 3 with enteric fever. Vitamin A deficiency noted in 2 children and nutritional dermatitis in 2 children.

\section{Discussion}

There was no statistically significant gender difference either in completion of facility care or sustained weight gain and follow ups as it is important to know the gender discrimination in the society.

Only 1 child had successfully been discharged with weight gain of $>15 \%(1.75 \%)$ at the time of discharge as compared to similar study by singh. $\mathrm{K}$ et al where $46.8 \%$ children were discharged after recovery (weight gain $>15 \%){ }^{7} 56 \%$ of children could achieve weight gain of WFH <-1SD at 4 follow ups (Fig. 3) as compared to 314 $(77 \%)$ in study done by kumar B et al. ${ }^{8}$

Participation of community health workers (Asha/AWW) was not satisfactory either in identifying and admitting SAM children to NRC or in follow up of discharged children at community level. Referral from RBSK was also not satisfactory. ${ }^{9}$ Good thing was excellent paediatricians 'effort in identifying, admitting and management of SAM during facility care at NRC.

The lack of satisfactory weight gain of $>15 \%$ and $>5 \mathrm{grams} / \mathrm{kg} / \mathrm{day}$ at the time of discharge from NRC can be attributed to lack of adequate counselling and involvement of mother in SAM food preparation and also monitoring the feeding of the children adequately by dietician / staff nurse. Purely milk based (F-75 and F100) formula can also be considered for no satisfactory weight gain. ${ }^{10}$ Other factors can be associated infections, anemia and lack of commitment by the mother in understanding and following the instructions given by NRC staffs.

Table 4: Chi-Square Test

\begin{tabular}{|l|c|c|c|}
\hline & Value & Df & Asymp. Sig. (2-sided) \\
\hline Pearson Chi-Square & $2.636^{\mathrm{a}}$ & 3 & $\mathrm{P}=0.451$ \\
\hline Likelihood Ratio & 3.064 & 3 & .382 \\
\hline Linear-by-Linear Association & .229 & 1 & .633 \\
\hline N of Valid Cases & 57 & & - The minimum expected count is \\
\hline $\begin{array}{l}\text { a. } 4 \text { cells (50.0\%) have expected count less than 5. The } \\
\text {.47. }\end{array}$
\end{tabular}

Table 5: SD for WFH at the time of admission

\begin{tabular}{|l|c|c|c|c|c|}
\hline \multirow{4}{*}{ Valid } & -4 & Frequency & Percent & $\begin{array}{c}\text { Valid } \\
\text { Percent }\end{array}$ & Cumulative Percent \\
\cline { 2 - 6 } & -3 & 4 & 7.0 & 7.0 & 7.0 \\
\cline { 2 - 6 } & -2 & 35 & 61.4 & 61.4 & 68.4 \\
\cline { 2 - 6 } & -1 & 17 & 29.8 & 29.8 & 98.2 \\
\cline { 2 - 6 } & Total & 1 & 1.8 & 1.8 & 100.0 \\
\hline
\end{tabular}

Table 6: SD for WFH at the time of discharge

\begin{tabular}{|l|c|c|c|c|c|}
\hline & & Frequency & Percent & $\begin{array}{c}\text { Valid } \\
\text { Percent }\end{array}$ & $\begin{array}{c}\text { Cumulative } \\
\text { Percent }\end{array}$ \\
\hline Valid & -4 & 1 & 1.8 & 1.8 & 1.8 \\
\cline { 2 - 6 } & -3 & 11 & 19.3 & 19.3 & 21.1 \\
\cline { 2 - 6 } & -2 & 33 & 57.9 & 57.9 & 78.9 \\
\cline { 2 - 6 } & -1 & 12 & 21.1 & 21.1 & 100.0 \\
\cline { 2 - 6 } & Total & 57 & 100.0 & 100.0 & \\
\hline
\end{tabular}

*Chi-square test for independence 

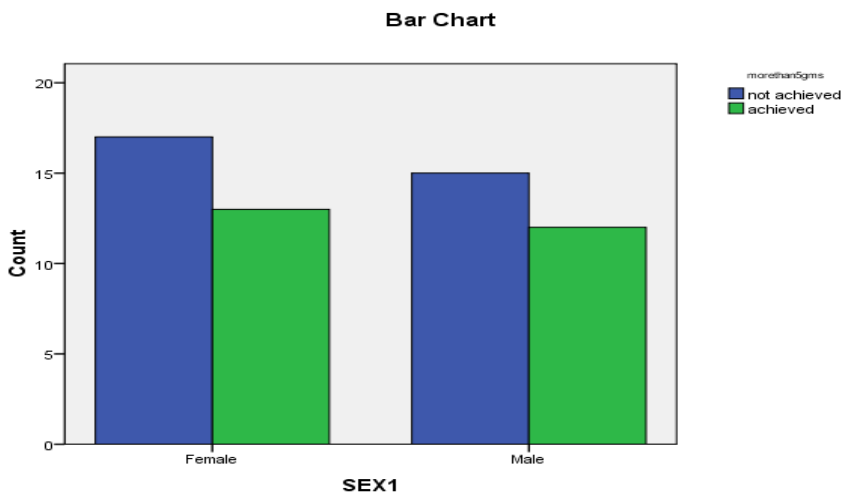

Fig. 2: Sex ratio gaining >5gms/kg/day

Hypothesis: There is no association between sex of child and gaining weight.

Table 7: Symmetric Measures

\begin{tabular}{|l|l|c|c|}
\hline & & Value & Approx. Sig. \\
\hline $\begin{array}{l}\text { Nominal by } \\
\text { Nominal }\end{array}$ & $\begin{array}{l}\text { Contingency } \\
\text { Coefficient }\end{array}$ & .011 & .933 \\
\hline \multicolumn{2}{|l|}{ N of Valid Cases } & 57 & \\
\hline
\end{tabular}

Using chi-square test for independence test we get $\mathrm{p}$ value as 0.933 at $1 \%$ level of significance we do not reject hypothesis and we conclude that there is no association between sex and weight gain.

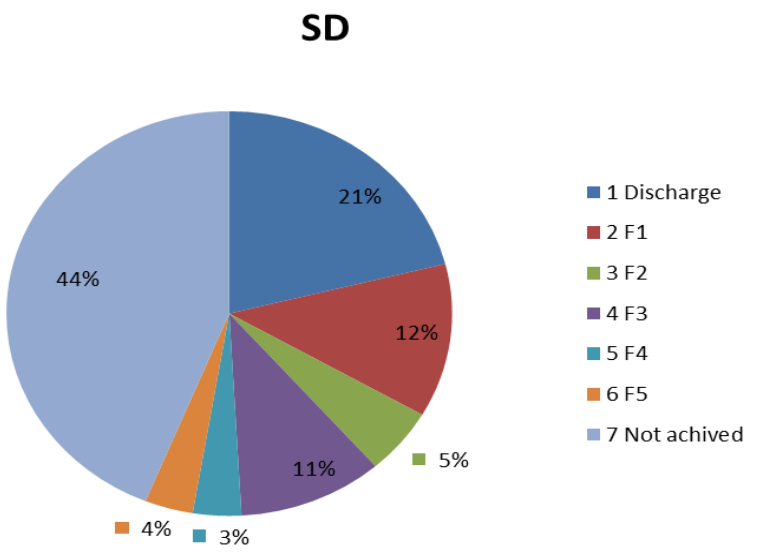

Fig. 3: Children achieved weight gain of <-1SD

\section{Conclusion}

In-patient care at NRC was effective in improvement in medical illnesses and management of general health but satisfactory weight gain at NRC could not be achieved as per national programme requirement either during inpatient care or during follow up visits.

The programmatic issues that have to be improved include better referral by health care workers and RBSK, involvement of mother in preparing food and proper counselling, monitoring of feeding of children at each scheduled feed by dietician/NRC staffs and proper integration of community and facility based management.

Complete cure of associated medical illnesses at NRC with sustained weight gain, children reaching <1SD during facilitation care as well as during follow up visits in $56 \%$ of children and good adherence to the follow up up to 2 months and beyond in $>93 \%$ of children were positive factors contributing to the success of the programme.

\section{Limitations of the study}

The study did not segregate SAM children into those with or without medical complications and only anthropometric measurements were considered. The study involved the review of existing hospital records, the complete reliability of which is questionable.

Funding: No funding sources.

Conflict of interest: None declared.

\section{References}

1. Management of severe acute malnutrition in children: Working towards results at scale; https://www.unicef.org/eapro/UNICEF_program_guidanc e_on_manangement_of_SAM_2015.pdf

2. NFHS-4 - National Family Health Survey; http://rchiips.org/nfhs/factsheet_NFHS-4.shtml

3. Operational Guidelines on Facility Based Management of Children with Severe Acute Malnutrition, Ministry of Health and Family Welfare Government of India, 2011. http://rajswasthya.nic.in/MTC\%20Guideline$\% 20 \mathrm{MOHFW}$

4. Ministry of Health and Family Welfare. National Rural Health Mission - meeting people's health needs in partnership with states: the journey so far, 2005-2010. New Delhi, India: Ministry of Health and Family Welfare 2010.

http://mohfw.nic.in/NRHM/Documents/5_Years_NRHM _Final.pdf Accessed November 2013. 
5. Ministry of Health and Family Welfare, Government of India. Operational guidelines on facility-based management of children with severe acute malnutrition. New Delhi, India: Government of India; 2011. http://rajswasthya.nic.in/MTC\%20Guideline$\% 20 \mathrm{MOHFW}$.pdf Accessed November 2013.

6. Bhatnagar S, Lodha R, Choudhury P, et al. IAP guidelines 2006 on hospital based management of severely malnourished children (adapted from the WHO Guidelines) Indian Pediatr 2007;44:443-61.

7. Singh K1, Badgaiyan N, Ranjan A, Dixit HO, Kaushik A, Kushwaha KP, Aguayo VM. Indian Pediatr 2014;51(1):21-5. Epub 2013 Jul 5. Management of children with severe acute malnutrition: experience of Nutrition Rehabilitation Centres in Uttar Pradesh, India.

8. Kumar B1, Shrivastava J2, Satyanarayana S3, Reid AJ4, Ali E4, Zodpey S1, Agnani M5. How effective is the integration of facility and community-based management of severe acute malnutrition in India? Public Health Action 2013;3(4):265-70. doi: 10.5588/pha.13.0058.
9. Tekeste A, Wondafrash M, Azene G, Deribe K. Costeffectiveness of community-based and in-patient therapeutic feeding programs to treat severe acute malnutrition in Ethiopia. Cost Eff Resour Alloc 2012;10:4

10. Taneja G, Dixit S, Khatri A, Yesikar V, Raghunath D, Chourasiya S. A study to evaluate the effect of nutritional intervention measures on admitted children in selected nutrition rehabilitation centers of Indore and Ujjain divisions of the State of Madhya Pradesh (India). Indian J Community Med 2012;37:107-15.

How to cite the article: S. Suguna. Outcome of management of severe acute malnutrition at nutrition rehabilitation centre and follow up. IP Int J Med Paediatr Oncol 2018;4(3):104-109. 